\title{
Photoluminescence from undoped silicon after chemical etching combined with metal plating
}

\author{
T. Hadjersi ${ }^{* 1}$, N. Gabouze ${ }^{1}$, N. Yamamoto ${ }^{2}$, K. Sakamaki ${ }^{3}$, H. Takai ${ }^{3}$, A. Ababou ${ }^{4}$, and \\ E.S. Kooij \\ ${ }^{1}$ Unité de Développement de la Technologie du Silicium (UDTS), 2, Bd. Frantz Fanon, \\ B.P. 399 Alger-Gare, Alger, Algeria \\ 2 Communications Research Laboratory, Basic and Advanced Research, Division, 4-2-1, \\ Nukui-kitamachi, Koganei,Tokyo, 184-8795, Japan \\ 3 Tokyo Denki University, Department of Electrical Engineering, 2-2 Kanda-Nishiki-cyo, Chiyoda-ku, \\ Tokyo, 101-8457, Japan \\ ${ }^{4}$ USTHB, Faculté d'électronique, BP 32 EL Alia Bab, Ezzouar, Alger, Algeria \\ ${ }^{5}$ Solid State Physics, MESA+ Research Institute, University of Twente, P.O. Box 217, \\ 7500 AE Enschede, The Netherlands
}

Received 25 July 2004, revised 3 November 2004, accepted 27 January 2005

Published online 9 June 2005

\section{PACS 68.37.Hk, 78.55.Mb, 81.05.Rm}

Photoluminescent porous layers were formed on highly resistive p-type silicon by metal-assisted chemical etching using $\mathrm{Na}_{2} \mathrm{~S}_{2} \mathrm{O}_{8}$ as an oxidizing agent. A thin layer of $\mathrm{Ag}$ was deposited on the (100) Si surface prior to immersion in a solution of $\mathrm{HF}$ and $\mathrm{Na}_{2} \mathrm{~S}_{2} \mathrm{O}_{8}$. The morphology of the porous silicon (PS) layer formed by this method as a function of etching time was investigated by scanning electron microscopy (SEM). It shows that the surface is porous and the thickness of PS layer increases with etching time and is not limited as observed with the electrochemical method. Energy-dispersive X-ray (EDX) was used to analyse the chemical composition of PS layers. The EDX spectra show that the metal is not present on the PS surface after etching. Photoluminescence (PL) from metal-assisted chemically etched layers was measured using a He-Cd laser as excitation source. It was found that the PL intensity increases with increasing etching time. However, it was shown that after an etching time of 30min, the fit of the PL spectrum using Gaussian functions exhibits two peaks centred at $617 \mathrm{~nm}$ and $646 \mathrm{~nm}$. This behaviour was attributed to an increase of the silicon nanostructure density.

() 2005 WILEY-VCH Verlag GmbH \& Co. KGaA, Weinheim

\section{Introduction}

Light emitting materials on a PS wafer have a great potential for use in optoelectronic industries. PS for light-emitting layers on a Si substrate can be formed by anodic (electrochemical) etching in HF based solutions $[1,2]$. However for low-doped crystalline and amorphous p-type silicon, due to an instability of the electrical field at the electrolyte/silicon interface, the thickness of the porous layer is limited [3]. The most attractive method that may be considered to increase the maximum thickness of PS is the stain etching $[4,5]$. The latter is relatively simple compared to the anodization method and it needs no electrodes on the back surface of Si wafers. However, the method requires a long etching time and is not uniform in producing PS layers. In addition, it provides PL intensities an order of magnitude smaller than

"Corresponding author: e-mail: hadjersi@yahoo.com, Phone: +21321 4335 11, Fax: +213 21433511 
conventional electrochemically etched PS [4]. Recently, we have used a new metal-assisted method, developed previously by Li et al. [6] on doped Si samples. We demonstrated that Pd-assisted chemical etching allows the formation of a PS on highly resistive silicon [7]. The method does not need an external bias and enables formation of uniform PS layers more rapidly than the conventional stain etching method. A thin metallic film ( $\mathrm{Au}, \mathrm{Pt}, \mathrm{Al}, \mathrm{Pd} \ldots)$ is generally deposited directly on a silicon surface prior to immersion in an etchant composed of HF and an oxidizing agent.

In this paper, we report on the formation of visible-light-emitting layers on highly resistive p-type silicon using $\mathrm{Na}_{2} \mathrm{~S}_{2} \mathrm{O}_{8}$ as an oxidizing agent and silver $(\mathrm{Ag})$ as deposited metal. We discuss the etching time dependence on the morphology of PS layers and the photoluminescence (PL) peak intensity. The changes in the PL spectrum are attributed to the structural modifications of PS layers caused by etching.

\section{Experiments}

The metal-assisted chemical etching processes are applied to p-type Si wafers CZ (100) 100 Ohm.cm. Thin silver films of about $200 \AA$ are evaporated under vacuum $\left(\sim 10^{-5}\right.$ Torr $)$ conditions onto the silicon samples. The etchant solution used is $22.5 \mathrm{M} \mathrm{HF}-0.05 \mathrm{M} \mathrm{Na}_{2} \mathrm{~S}_{2} \mathrm{O}_{8}-\mathrm{H}_{2} \mathrm{O}$. After etching the samples are rinsed with deionised water. The etching is performed at room temperature. The time of etching is varied between $30 \mathrm{~s}$ and $1 \mathrm{~h}$.

For the SEM measurements, a Philips XL 30 microscope is used which is equipped with a Energydispersive X-ray analyzer (EDX). Chemical analyses are performed by EDX. Photoluminescence (PL) from the Ag-assisted chemically etched silicon is measured under He-Cd laser excitation (325 nm), in vacuum $\left(<10^{-2}\right.$ Torr $)$, by a monochromator and photomultiplier tube.

\section{Results and discussion}

The plane and cross sectional views provide information on the geometry of the horizontal and vertical cross-section of pores, respectively. Figure 1a depicts a plane view SEM image of a p-Si (100) sample $(100 \Omega . c m)$ which was subjected to Ag-assisted chemical etching in $22.5 \mathrm{M} \mathrm{HF}-0.05 \mathrm{M} \mathrm{Na}_{2} \mathrm{~S}_{2} \mathrm{O}_{8}-\mathrm{H}_{2} \mathrm{O}$ solution for $15 \mathrm{~min}$. It shows that the surface is porous and has a sponge-like structure. The crosssectional SEM view of the same sample shows the presence of a porous layer with a thickness of about $2.5 \mu \mathrm{m}$ (Fig. 1b).
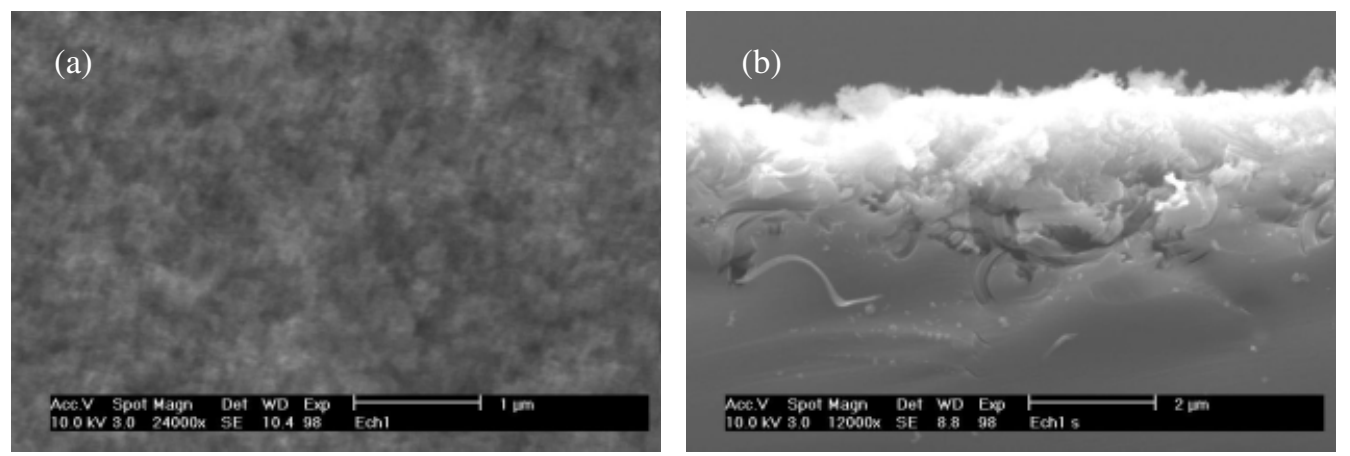

Fig. 1 Plan (a) and cross sectional (b) view SEM images of $\mathrm{Si}(100)$ with a resistivity of $100 \Omega$.cm after etching in 22.5 HF-0.05 $\mathrm{M} \mathrm{Na}_{2} \mathrm{~S}_{2} \mathrm{O}_{8}-\mathrm{H}_{2} \mathrm{O}$ solution for $15 \mathrm{~min}$. A thin film of $\mathrm{Ag}$ was deposited before etching.

Figures $2 \mathrm{a}$ and $2 \mathrm{~b}$ show that the increase of the etching time leads to a remarkable evolution in the surface morphology. Increasing the etching time induces an increase in pore diameter. In addition, it is observed that extended etching times to 30 and $60 \mathrm{~min}$ lead to an increase of the PS layer thickness to 
about 10 and $13 \mu \mathrm{m}$, respectively. An examination of the cross sectional SEM view of the sample etched for $60 \mathrm{~min}$ at high magnification shows that the porous layers are formed by a high density of macropores propagating into the bulk from the surface in a random manner (Fig. 3). This morphology is quite different from that observed on Pd-metal assisted chemically etched PS obtained on high resistivity silicon [7]. Indeed, in the latter case, it shows the presence of a low density of macropores propagating into the bulk from the surface with no specific orientation relative to the underlying substrate crystal structure, indicating that macrodissolution is more favoured when Ag is deposited on the silicon surface. This denotes that the morphology of etched layer depends on the type of the deposited metal before etching. In addition, from cross sectional SEM views ( Figs. $1 \mathrm{~b}$ and 3), there is no clear interface between the PS film and substrate as observed on electrochemically anodized low doped p-type silicon, where macropores propagate anisotropically, perpendicular to the surface and the interface between the PS layer and substrate is reasonably well-defined [3].
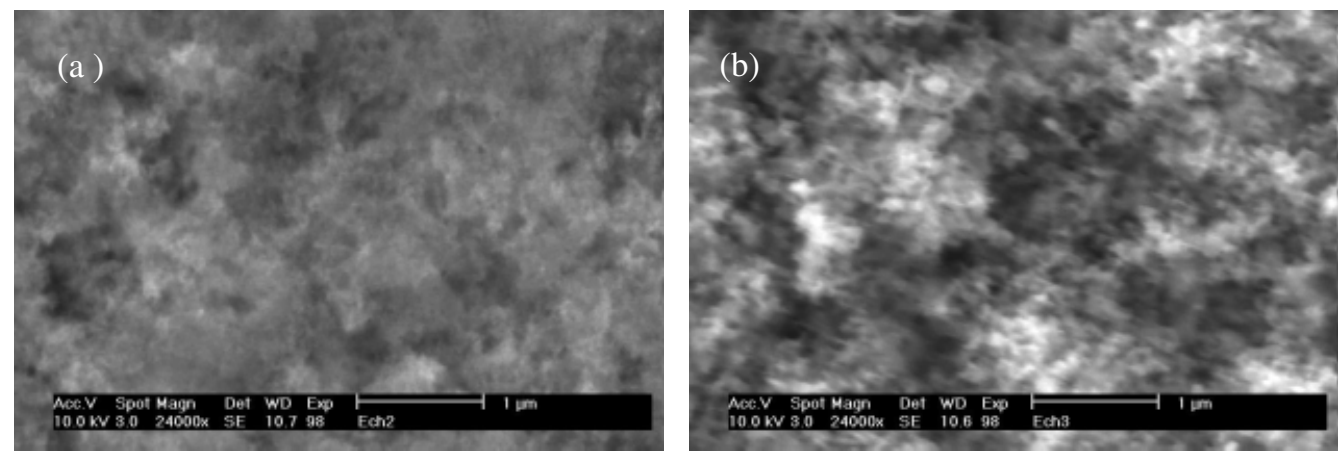

Fig. 2 Plan view SEM images of $\mathrm{Si}(100)$ with a resistivity of $100 \Omega . \mathrm{cm}$ after etching in $22.5 \mathrm{HF}-0.05 \mathrm{M} \mathrm{Na}_{2} \mathrm{~S}_{2} \mathrm{O}_{8}-$ $\mathrm{H}_{2} \mathrm{O}$ solution. (a) for $30 \mathrm{~min}$ and (b) for $60 \mathrm{~min}$. A thin film of $\mathrm{Ag}$ was deposited before etching.

Analysis of the silicon surface by EDX after evaporation of thin silver film shows the presence of two peaks, corresponding to silicon and silver. However, after chemical etching the silver peak has disappeared and only the presence of silicon is observed, Fig. 4. We can suggest that the deposited metal does not remain on the PS surface and dissolves completely in the solution after etching. Thus, we can deduce that the deposited metal initiates the etching. In the subsequent etching procedure, the metal does not play a role. These results are in agreement with those reported previously by Hadjersi et al. [7].

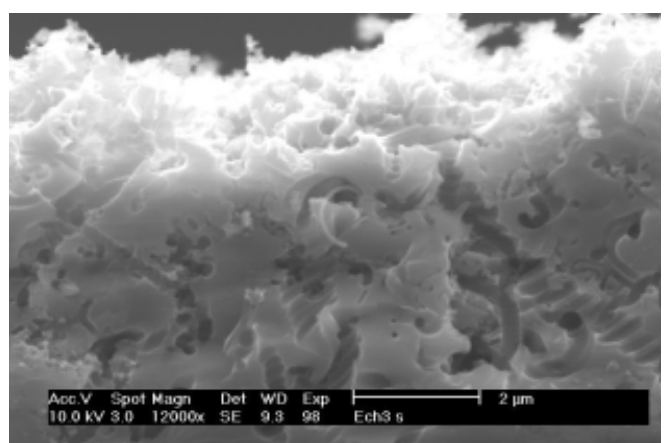

Fig. 3 Cross sectional SEM images of Ag-assisted chemically etched silicon (100) with a resistivity of $100 \Omega . \mathrm{cm}$ for $60 \mathrm{~min}$.

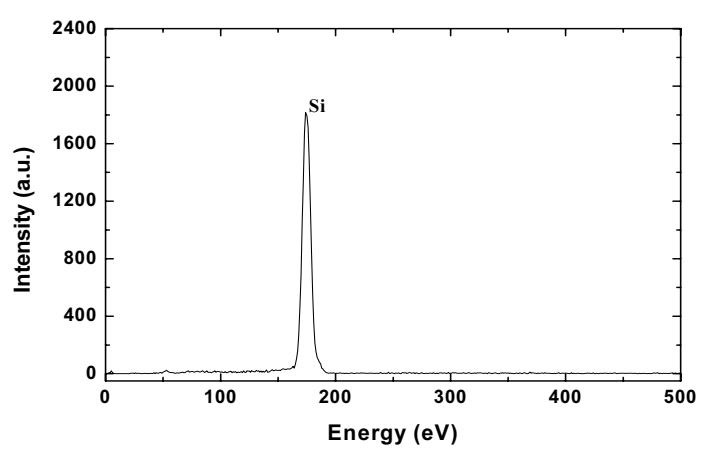

Fig. 4 Energy dispersive X-ray spectrum of a PS layer formed on highly resistive silicon $(100 \Omega . \mathrm{cm})$ by treatment in a $22.5 \mathrm{HF}-0.05 \mathrm{M} \mathrm{Na}_{2} \mathrm{~S}_{2} \mathrm{O}_{8}-\mathrm{H}_{2} \mathrm{O}$ solution for $30 \mathrm{~min}$. 
Figure 5 shows the dependence of PL spectra on the etching time. It clearly shows that the PL peak intensity increases with increasing etching time. This fact can be related to the increase of the silicon nanostructures density, i.e. of radiative recombination centers, which is in agreement with SEM observations.

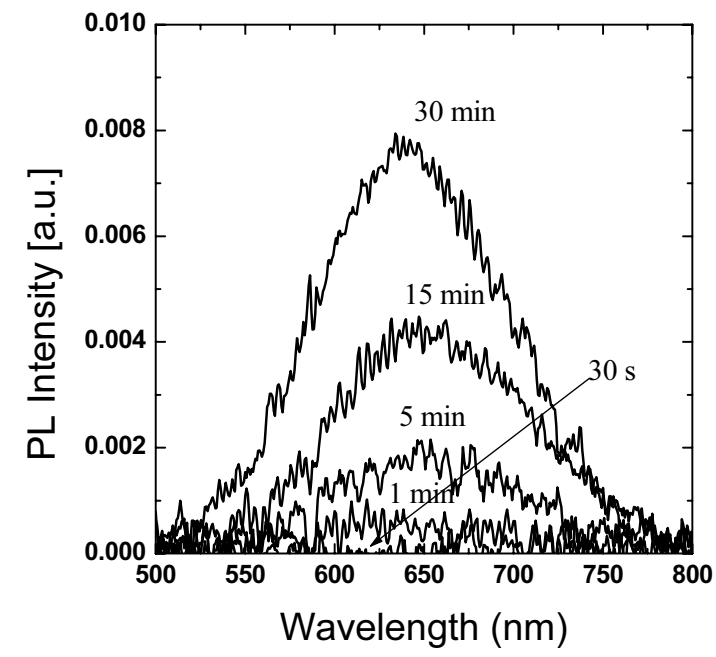

Fig. 5 Photoluminescence spectra as a function of the etching time taken from $\mathrm{Ag}$-assisted chemically etched silicon on p-type $\mathrm{Si}(100)$ with a resistivity of $100 \Omega . \mathrm{cm}$.

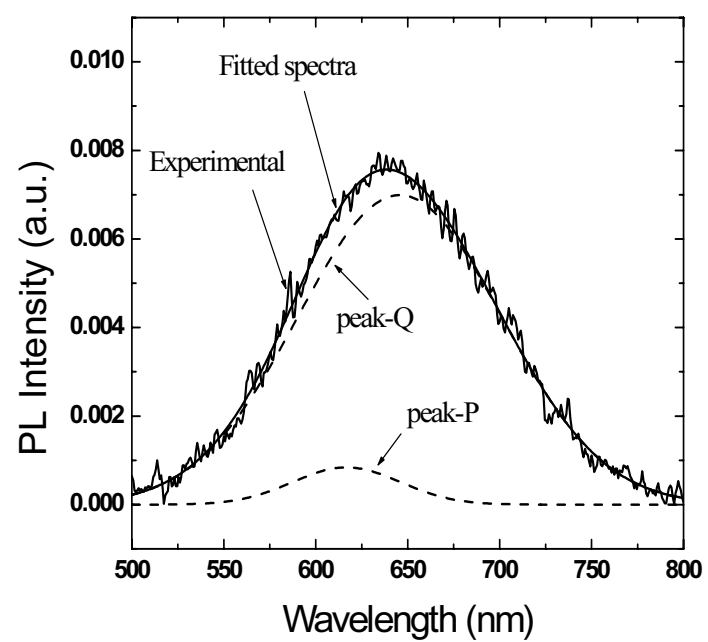

Fig. 6 Separated PL spectra of Ag-assisted chemically etched for $30 \mathrm{~min}$.

This result is very interesting, since it is difficult to form a light-emitting porous layers on highly resistive silicon by the electrochemical method. For etching times lower than $30 \mathrm{~min}$, the etched layers exhibit strong red luminescence with a PL peak centred at $655 \mathrm{~nm}$ and a FWHM width of $0.3 \mathrm{eV}$, which are similar to those found for medium doped anodically etched silicon [8]. However, for an etching time of $30 \mathrm{~min}$, the etched layer exhibits a bright red emission and a wide PL spectrum from $1.7 \mathrm{eV}$ to $2.1 \mathrm{eV}$. It is also important to note that the PL spectrum peak of the sample etched for $30 \mathrm{~min}$ is not perfectly Gaussian. Since the visible luminescence spectra of common PS have a shape close to a Gaussian curve, the assumption that the luminescence spectrum, for etching time of $30 \mathrm{~min}$, can be fitted by addition of several Gaussian curves (peaks) is appropriate.

4 Indeed, figure 6 shows that it can be fitted by a sum of two Gaussian curves, with two peaks centred at $617 \mathrm{~nm}$ (peak-P) and $646 \mathrm{~nm}$ (peak-Q). According to the quantum confinement model, the emission wavelength and the PL peak intensity are correlated to nanocrystallite size and the number (density) of nanocrystallites, respectively [9]. We can deduce that for etching times lower than $30 \mathrm{~min}$, there is a distribution of nanocrystallite sizes, since the PL peak shows a certain width, and their sizes are close to each other so that they emit at wavelengths around $655 \mathrm{~nm}$. However, for etching time of $30 \mathrm{~min}$ we can suggest the presence of two types of nanocrystallites: the first type having sizes corresponding to the wavelength emission around $646 \mathrm{~nm}$ (peak-Q), on the other hand, the second type having sizes smaller than those of first type that emit at wavelength around $617 \mathrm{~nm}$ (peak-P). The PL intensity corresponding to peak-P is smaller than that of peak-Q, therefore the nanocrystallite density of second type is predominant. In addition, the sizes of nanocrystallites of the sample etched for $30 \mathrm{~min}$ are smaller compared to those of samples etched for $15 \mathrm{~min}$ or shorter. Because the emission wavelengths for an etching time of $30 \mathrm{~min}$ are smaller than for $15 \mathrm{~min}$ or lower. It seems that when the etching time increases from $15 \mathrm{~min}$ to $30 \mathrm{~min}$, the nanocrystallite size decreases leading to a shift of PL peak from $655 \mathrm{~nm}$ to $646 \mathrm{~nm}$ and at the same time there is a creation of new nanocrystallites with low density having a small size that emit 
around $617 \mathrm{~nm}$. A strong luminescence is observed from samples etched for $15 \mathrm{~min}$ and 30 min with the naked eye in daylight.

These results differ from those found by $\mathrm{Li}$ et al., where PL peaks were centred at $590 \mathrm{~nm}$ [6]. This is most likely due to preparation conditions and resistivity of samples that have produced a morphology different from that of our samples. Indeed, they used doped Si samples and deposited a thin film of platinum on the silicon surface prior to immersion in a solution of $\mathrm{HF}$ and $\mathrm{H}_{2} \mathrm{O}_{2}$. Thus, large pores with columnar structure were formed. This confirms that different morphologies can be produced by varying either the type of metal, the dopant level, the dopant type, or the type of etchant solution.

\section{Conclusions}

It has been demonstrated that the Ag-assisted chemical etching method allows formation of a photoluminescent PS layer on highly resistive silicon, which is very difficult using the electrochemical method. We have observed that the thickness of the etched layers increases with etching time. The morphology of the etched layer formed by this method is not similar to that obtained by the electrochemical etching method on low resistivity silicon. Indeed, macropore propagating in an isotropic manner from the surface to the bulk are observed and the interface between the PS layer and substrate is not well defined. The deposited silver initiates the chemical etching and dissolves completely in the solution. We have shown that the PL intensity increases with increasing etching time, which can be attributed to the increase of the silicon nanostructures density in agreement with the quantum confinement model prediction. Finally, the PL spectra peaked at $655 \mathrm{~nm}$ for etching time lower than $30 \mathrm{~min}$. On other hand for etching time of $30 \mathrm{~min}$ the PL spectrum can been fitted by addition of two Gaussian curves indicating that there are two emission maxima, $617 \mathrm{~nm}$ and $646 \mathrm{~nm}$.

Acknowledgements The SEM images shown in this work was provided by D. Sahel and N. Soualmi Their assistance is gratefully appreciated.

\section{References}

[1] V. Lehmann and U. Gosele, Appl. Phys. Lett. 58, 856 (1991).

[2] Y. Kanemitsu, Phys. Rev. B 48, 4883 (1993).

[3] J.-N. Chazalviel, F. Ozanam, N. Gabouze, S. Fellah, and R.B. Wehrspohn, J. Electrochem. Soc. 149, C511 (2002).

[4] S. Shih, K.H. Jung, T. Y. Hsieh, J. Sarathy, J. C. Campbell, and D. L. Kwong, Appl. Phys. Lett. 60, 1863 (1992).

[5] M. Schoisswohl, J. L. Cantin, and H. J. von Bardeleben, Appl. Phys. Lett. 66, 3660 (1995).

[6] X. Li and P. W. Bohn, Appl. Phys. Lett. 77, 2572 (2000).

[7] T. Hadjersi, N. Gabouze, E.S. Kooij, A. Zinine, A. Ababou, W. Chergui, H. Cheraga, S. Belhousse, and A. Djeghri, Thin Solid Films 459, 271 (2004).

[8] L. T. Canham, Appl. Phys. Lett. 57, 1046 (1990)

[9] G. Ledoux, O. Guillois, D. Porterat, C. Reynaud, F. Huisken, B. Kohn, and V. Paillard, Phys. Rev. B 62,15942 (2000). 